\title{
Occupational lung disease
}

\author{
${ }^{1}$ PA Reid, ${ }^{2}$ PT Reid \\ ${ }^{1}$ Specialist Registrar in Respiratory Medicine, Department of Respiratory Medicine, Royal Infirmary of Edinburgh, UK; ${ }^{2}$ Consultant \\ Respiratory Physician, Department of Respiratory Medicine, Western General Hospital, Edinburgh, UK
}

ABSTRACT Occupational medicine represents the interface between work and health. As such, its breadth encompasses issues of clinical medicine, epidemiology, occupational hygiene, toxicology, ethics, and the law. The diagnosis of an occupational lung disease has implications not only for the health of the worker, but also in some circumstances for the health of colleagues and the employer. It is not surprising that many clinicians find this challenging. The aim of this paper is to provide a summary of common work-related lung disorders, and stress the importance of considering a patients' occupation when presented with a range of respiratory symptoms.

KEYWORDS Occupation, asthma, pneumoconioses, asbestos, silica, mesothelioma
Correspondence to PT Reid Department of Respiratory Medicine

Western General Hospital

Crewe Road

Edinburgh EH4 2XU, UK

tel. +44 (0) I3। 537 I768

e-mail

Peter.Reid@nhslothian.scot.nhs.uk

DECLARATIONS OF INTERESTS No conflicts of interest declared.

\section{OBSTRUCTIVE OCCUPATIONAL AIRWAY DISEASE}

\section{Occupational asthma}

Occupational asthma (OA) remains the most commonly recognised industrial lung disease in the developed world; however, many cases remain unreported. The symptoms are similar to other forms of asthma except that they are linked to exposure to an agent that is encountered specifically in the occupational environment (Figure I). Occupational asthma refers to the development of asthma following exposure to a known occupational sensitiser (often with evidence of an elevated specific immunoglobulin $E$ [IgE] to the relevant occupational allergen). The first clue that asthma may be linked to occupation is usually found in the history, if the patient reports improvement in symptoms occurring at weekends and on holidays. Rhinoconjuctivitis is often present and may precede the onset of lower respiratory tract symptoms. Establishing the link between symptoms to an agent at work often requires a methodical work-up including more detailed lung function tests. Objective confirmation of work-related symptoms may be

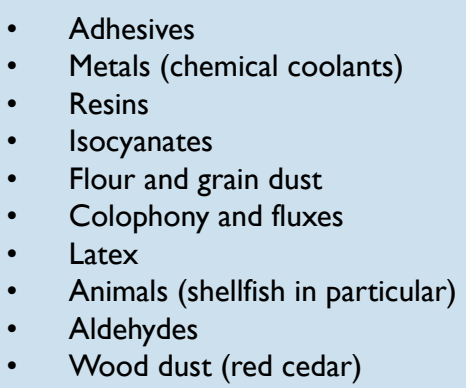

FIGURE I Agents causing occupational asthma (OA).

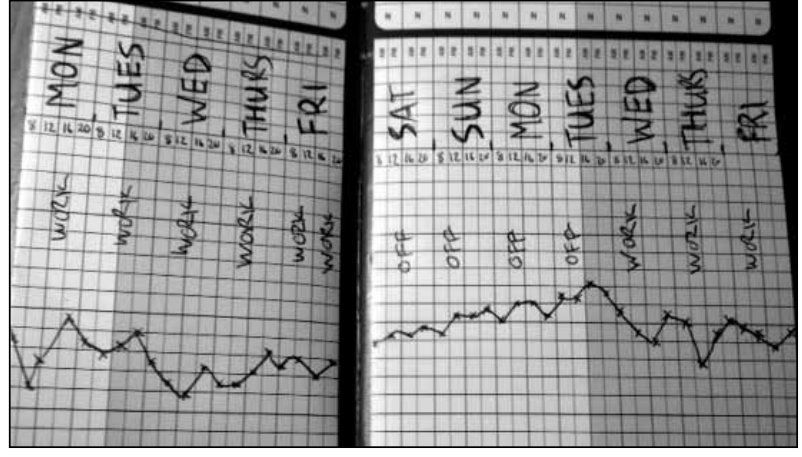

FIGURE 2 Peak expiratory flow rate (PEFR) diary for a 36-year-old baker with suspected occupational asthma.

achieved by the use of serial peak flow recording (usually at least four times per day for a period of at least three weeks, and if possible including a period away from work) (Figure 2) or by changes in airway hyper-reactivity during periods at and away from work. In specific circumstances, specific provocation tests using the suspected agent may be employed. In some circumstances sensitisation may be demonstrated by skin testing or the measurement of an elevated specific $\lg$ antibody to the agent in question.

Acknowledgement that early recognition and intervention improves the prognosis reinforces the importance of surveillance, particularly in occupations known to be at high risk of OA (Figure 3). Workers should report any relevant symptoms as soon as they develop and at-risk workers should be provided with health surveillance at least annually and more frequently in the first years of exposure.

The management of occupational asthma involves a number of different healthcare professionals working together with the patient and, on occasion, the employer. 
- Animal handlers

- Bakers and pastry makers

- Chemical workers

- Food processing workers

- Hairdressers

- Paint sprayers

- Nurses

- Timber workers

- Welders

FIGURE 3 Occupations at risk of occupational asthmas (OA).

Both clinical and economic implications need to be considered. Removal from the trigger (when possible and when the trigger is identified) may be an important component of management; however, consideration of occupational hygiene and personal protective equipment may allow the worker to retain their job and their livelihood. When OA is detected early and the exposure mitigated, the prognosis may be good. However, in many cases, OA persists as a chronic condition and specialist follow-up in these situations is desirable.

\section{Reactive airways dysfunction syndrome}

The term reactive airways dysfunction syndrome (RADS) refers to the development of a persistent asthma-like syndrome for at least three months following inhalation of an airway irritant. The onset of symptoms occurs after a single specific exposure to a gas, smoke, fume, or vapour in very high concentrations. It is sometimes referred to as irritant-induced asthma. The most commonly reported agent causing RADS is chlorine. Other commonly reported agents include toluene diisocyanate, oxides of nitrogen, acetic acid, sulphur dioxide, and certain paints. The onset of symptoms, which are typical of asthma, occur within 24 hours of exposure. Pulmonary function tests may show airflow obstruction and airway hyper-reactivity. The management of RADS/irritant-induced asthma is little different from that for any other person with asthma. The prognosis is more uncertain. In some it is a selflimiting disease but many patients continue to report persistent symptoms.

\section{Occupational chronic obstructive pulmonary disease}

Chronic obstructive pulmonary disease (COPD) is an umbrella term that encompasses several different pathologies, most notably chronic bronchitis, small airways disease and emphysema, and is defined by airflow limitation that is usually progressive. Cigarette smoking remains the most important cause of COPD but inhalation of noxious particles or gases encountered in an occupational setting make an important contribution to COPD. Most notably, these include coal dust, cotton textiles, welding vapours, cadmium and silica.

\section{PNEUMOCONIOSES}

\section{Coal-worker's pneumoconiosis}

Coal worker's pneumoconiosis (CWP) results from the inhalation of particles of coal mine dust, which are engulfed by macrophages which then accumulate to form the coal macule, characteristically located in the centrilobular region (Table I). Pneumoconiosis appears on the chest X-ray as small rounded opacities, typically appearing in upper and middle zones. Simple coal worker's pneumoconiosis is not associated with abnormal clinical signs or significant impairment of lung function. If breathlessness and lung function impairment are present they are likely to be due to associated lung or heart disease. Progressive massive fibrosis (PMF) refers to the coalescence of macules to form irregular masses of fibrous tissue. It usually occurs against a background of simple pneumoconiosis and is associated with increasing impairment of lung function and symptoms (Figure 4).

TABLE I Particulate causes and at-risk occupations for pneumoconiosis

\begin{tabular}{|l|l|l|}
\hline Mineral dust & Disease & Occupation \\
\hline Coal dust & $\begin{array}{l}\text { Coal worker's } \\
\text { pneumoconiosis }\end{array}$ & Coal mining \\
\hline $\begin{array}{l}\text { Silica (crystalline } \\
\text { quartz) }\end{array}$ & Silicosis & $\begin{array}{l}\text { Foundry worker, } \\
\text { sandblasting, stone } \\
\text { cutting, hard rock } \\
\text { mining }\end{array}$ \\
\hline Beryllium & $\begin{array}{l}\text { Acute berylliosis, } \\
\text { Beryllium } \\
\text { granulomatosis }\end{array}$ & $\begin{array}{l}\text { Mining, milling, } \\
\text { installation/removal } \\
\text { of insulation }\end{array}$ \\
\hline Iron oxide & Siderosis & Welding \\
\hline Barium sulphate & Baritosis & Mining \\
\hline Tin oxide & Stannosis & Mining \\
\hline Aluminium & $\begin{array}{l}\text { Bauxite workers } \\
\text { lung, Shaver's } \\
\text { disease }\end{array}$ & $\begin{array}{l}\text { Mining, fireworks, } \\
\text { painting }\end{array}$ \\
\hline
\end{tabular}

\section{Silicosis}

Crystalline silica is one of the most abundant minerals on earth; it is found in substantial quantities in sand, sandstone and granite, and often forms a significant proportion of clay, shale and slate. Workplace activities such as cutting, grinding and polishing produce fine dusts that contain respirable crystalline silica. There are three main clinical presentations of silicosis: classic silicosis, accelerated silicosis and silicoproteinosis.

Classic silicosis is the most common presentation of the condition (Figure 5). Patients usually remain asymptomatic until after an interval of 10-20 years of continuous silica exposure.Accelerated silicosis is associated with a much shorter duration of dust exposure (typically $5-10$ years) 


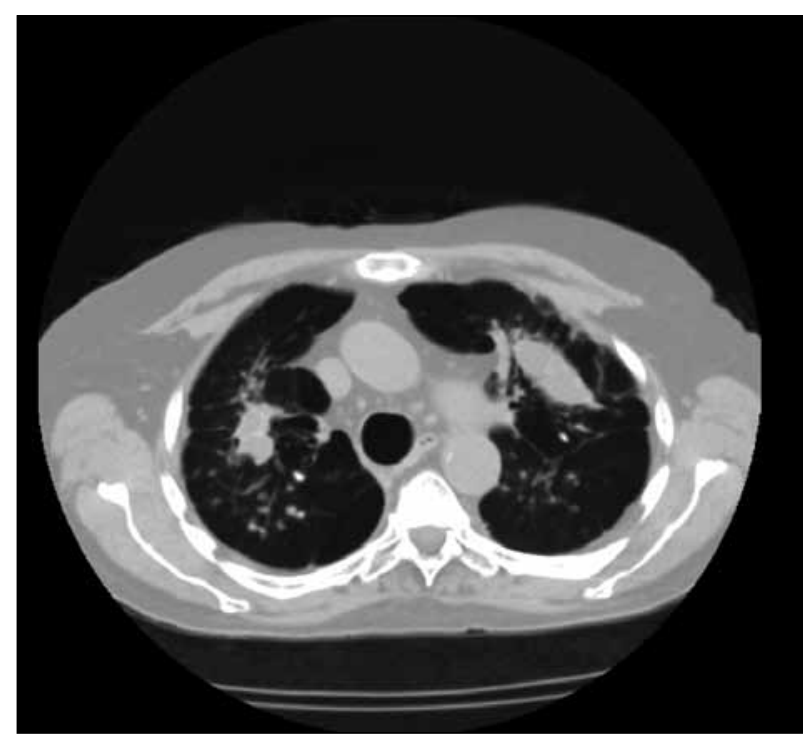

FIGURE 4 Coal worker's pneumoconiosis with progressive massive fibrosis (PMF). Multiple small lung nodules with an upper lobe predominance and conglomeration of nodules within the upper lobes in keeping with PMF. Emphysema is also present.

and, as the name suggests, a faster rate of disease progression. Clinical presentation may be as early as one year after exposure. Otherwise, the clinical, radiographic, and pathological features are similar to classic silicosis. Silicoproteinosis is acute and rapidly progressive following very high levels of exposure. Presentation within one year of exposure and death within five years of exposure have been reported.

Once silicosis occurs the damage is irreversible and, in contrast to coal worker's pneumoconiosis, the condition may continue to progress after the individual is removed from the exposure. Although subjects may be asymptomatic, as the condition progresses increasing levels of breathlessness can be anticipated. Pulmonary hypertension, respiratory failure and corpulmonale, and right heart failure may complicate the care. Other diseases linked to the inhalation of silica include lung cancer, tuberculosis, opportunistic mycobacterial infection, renal failure and connective tissue disease.

\section{Asbestosis}

Asbestosis is a fibrosing condition of the lungs caused by inhalation of substantial asbestos dust (Figure 6). Its appearance is usually preceded by a lag period of around 20 years and often much longer. It is usually slowly progressive with patients presenting with exertional breathlessness and a dry cough. Late inspiratory crackles and finger clubbing may be present. Lung function testing shows features of a diffuse parenchymal lung disease; namely a restrictive ventilatory defect, reduced lung volumes, and impaired gas transfer. The condition may be diagnosed on chest radiography but high-resolution computed tomography (CT) scanning is now the investigation of choice.

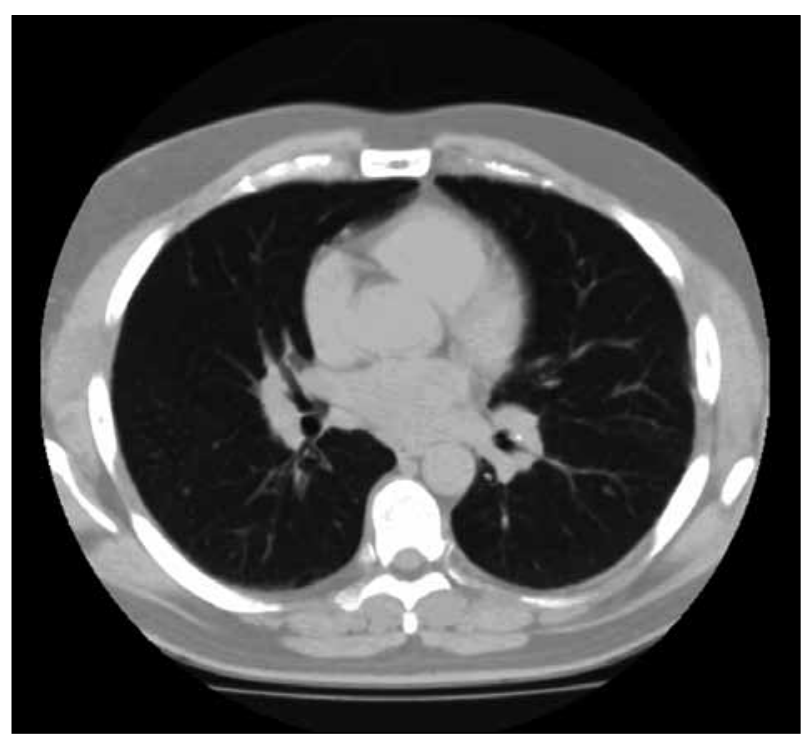

FIGURE 5 Silicosis. Multiple predominantly small lung nodules in the mid and upper zones. Hilar and mediastinal lymph node prominence with calcification at the left hilum.

- $\quad$ Mining, milling
- $\quad$ Railway engineering
- $\quad$ Fonstruction and demolition
- $\quad$ Ship building insulation, fireproof textiles
- $\quad$ Car mechanics (brake lining)
- Pipe and boiler fitting, lagging

FIGURE 6 Occupations with likely asbestos exposure.

Typical CT scan findings include the presence of subpleural dot-like opacities, curvilinear subpleural lines, ground glass opacification, and interlobular septal thickening. In more advanced disease, honeycombing may be present and typically predominates in the peripheral posterior lung. Severe cases of asbestosis may lead to the development of respiratory failure and death.

\section{HYPERSENSITIVITY PNEUMONITIS}

Hypersensitivity pneumonitis (previously called extrinsic allergic alveolitis) refers to an allergic inflammatory pneumonitis following the repeated inhalation of organic material.Workers at risk include those with exposure to moulds or fungal spore in agriculture, horticulture, forestry, cultivation of edible fungi or maltworking, those handling mouldy vegetables and those caring for or handling birds. Many of the classical forms have memorable names such as farmer's lung, malt worker's lung, mushroom worker's lung and bird fancier's lung. Recent attention has been drawn to the role of metalworking fluids (MWF) with three outbreaks reported in the UK probably occurring as a result of microbial contamination of MWF dispersed in the factory as a respirable mist. The disease has two patterns: the acute form, which presents like a non-specific pneumonic illness, 
and the chronic form, which is manifested by a fibrotic disease affecting the upper lobes. History taking is crucial as most biochemical tests have a low yield. Lung biopsy characteristically shows a mixture of three pathologies: lung fibrosis, alveolitis and granuloma formation.

\section{OCCUPATIONAL RESPIRATORY CANCERS}

\section{Mesothelioma}

The most notorious occupational cancer in respiratory practice is pleural mesothelioma. Its occurrence almost invariably suggests past asbestos exposure which may have been low level, and even bystander, exposure. The long latency between exposure and presentation suggests that the incidence of mesothelioma will continue to increase. It is likely to peak between $201 \mathrm{I}$ and 2015 . Pleural mesothelioma typically presents with increasing breathlessness resulting from pleural effusion or unremitting chest pain reflecting involvement of the chest wall. As the tumour progresses it encases the underlying lung and may invade into the parenchyma, the mediastinum, and the pericardium. Metastatic disease, although not often clinically detectable in life, is a common finding on post-mortem. Mesothelioma is almost invariably fatal. Highly selected patients may be considered for radical surgery but in the majority of patients, therapy is invariably directed towards palliation of symptoms. The use of chemotherapy may improve quality of life and is accompanied by a small survival benefit, typically quoted as around three months. Radiotherapy can be used to control pain and limit the risk of tumour seeding at biopsy sites. Pleural effusions are managed with drainage and pleurodesis. Typical figures for survival from onset of symptoms are around 16 months for epithelioid tumours, ten months for sarcomatoid tumours and 15 months for biphasic tumours.

\section{Lung cancer}

The current epidemic of lung cancer is almost entirely due to the exponential rise in tobacco smoking observed throughout the twentieth century; however, an increased risk of lung cancer in persons exposed to substantial quantities of asbestos, silica and coke is accepted and a thorough history should include enquiry into any relevant exposure. Concerns have been expressed in regard to an increased risk of lung cancer in workers exposed to beryllium; however, to date there is insufficient evidence on which to draw firm conclusions.
They are virtually always asymptomatic, and identified as an incidental finding on a chest radiograph or thoracic CT scan, particularly when partially calcified. Plaques should be differentiated from diffuse pleural thickening (DPT) which refers to thickening of the visceral pleura. In contrast to plaques, if sufficiently extensive, DPT may cause restrictive lung function impairment, breathlessness, and, occasionally, chest pain. The typical appearances of DPT on chest radiograph include thickening of the pleura along the chest wall and obliteration of the costophrenic angles. Earlier manifestations of DPT may be detected by CT scanning. For example, parenchymal bands suggest moderate visceral pleural fibrosis and occasionally contraction of the visceral pleura may lead to the appearance of 'round atelectasis'. There is no treatment although in exceptionally severe cases, surgical decortication may be considered. A pleural biopsy may be required to exclude mesothelioma.

\section{SUMMARY}

This review has, by necessity, focused on a small number of important conditions. Many others remain to be discussed such as metal fume fever, occupational infections such as Legionnaire's disease, $\mathrm{Q}$ fever, and brucellosis. Another important area we have not touched upon is the effect of health on the ability to work. Hopefully the reader will enjoy and be prompted to read further.

\section{Highlights}

- Occupational asthma (OA) is the commonest industrial lung disease but remains significantly underestimated.

- Early recognition and intervention in occupational asthma $(O A)$ improves the prognosis and reinforces the importance of surveillance, particularly in occupations known to be at high risk of OA.

- Silicosis is irreversible and, in contrast to coal worker's pneumoconiosis, the condition may continue to progress after the individual is removed from the exposure.

- Pleural plaques are the commonest manifestation of past asbestos exposure and are virtually always asymptomatic.

- The legacy of past asbestos use continues to drive an increasing incidence of mesothelioma. The prognosis for this cancer remains poor.

\section{PLEURAL DISEASE}

\section{Asbestos-related pleural disease}

Pleural plaques are the most common manifestation of past asbestos exposure. They are discrete circumscribed areas of hyaline fibrosis found on mainly parietal pleura. 


\section{FURTHER READING}

I American Thoracic Society. Adverse effects of crystalline silica exposure. Am J Respir Crit Care Med 1997; I55:76I-8.

2 British Occupational Health Research Foundation (BOHRF) [Internet]. Occupational asthma: identification, management and prevention: evidence based review and guideline. London: BOHR;20I0 [cited 2013 Feb 15].Available from: http://www.bohrf.org.uk/ downloads/OccupationalAsthmaEvidenceReview-Mar2010.pdf

3 British Thoracic Society Standards of Care Committee. BTS statement on malignant mesothelioma in the UK, 2007. Thorax 2007; 62:ii I-ii I 9. http://dx.doi.org//0.I I36/thx.2007.0876/9
4 Fishwick D, Barber CM, Bradshaw LM. et al. Standards of care for occupational asthma. British Thoracic Society Standards of Care Subcommittee Guidelines on Occupational Asthma. Thorax 2008; 63:240-50. http://dx.doi.org/ I0.I I36/thx.2007.083444

5 Rudd RM. Asbestos-related disease. In: Gibson G], Geddes DM, Costable $U$ et al (eds). Textbook of respiratory medicine (3rd ed). Saunders, London; 2003.

6 Hodgson JT, McElvenny DM, Darnton AJ et al. The expected burden of mesothelioma mortality in Great Britain from mesiothelioma from 2002 to 2050. Br J Cancer 2005; 92: 587-93.

\section{SELF-ASSESSMENT QUESTIONS}

I. Which ONE of the following is NOT a recognised complication of silica exposure?

Choose ONE answer

A. Mycobacterium tuberculosis infection.

B. Bronchogenic carcinoma.

C. Non-tuberculous mycobacterium infection.

D. Pulmonary hemorrhage.

E. Glomerulonephritis.

2. Which ONE of the following is inconsistent with occupational asthma (OA)?

Choose ONE answer

A. Improvement of symptoms on days away from work.

B. Deterioration of symptoms at work.

C. Dysphonia.

D. Nocturnal cough and wheeze.

E. Respiratory symptoms commencing within one year of commencing employment.

3. Which ONE of the following statements on asbestos-related lung disease is CORRECT? Choose ONE answer

A. Asbestosis typically presents following five years of intermittent low level asbestos exposure.

B. Pleural plaques commonly cause breathlessness and chest pain.

C. Extensive diffuse pleural thickening typically causes a obstructive ventilatory defect.

D. Round atelectasis is a manifestation of benign pleural disease.

E. In mesothelioma survival beyond 18 months from diagnosis is uncommon.
4. Which ONE of the following exposures has the strongest association with the development of lung cancer?

Choose ONE answer

A. Carbon.

B. Beryllium.

C. Chlorine is the commonest cause for occupational chronic obstructive pulmonary disease (COPD).

D. Coke.

E. Tin.

5. Which ONE of the following is TRUE with regard to occupational asthma (OA)?

Choose ONE answer

A. Clinical suspicion is enough of a basis for diagnosis and commencing treatment.

B. A short symptomatic history indicates favourable prognosis.

C. Workers with occupational asthma must be removed from the workplace.

D. The diagnosis needs to be reconsidered if symptoms persist for several months after removal of exposure.

E. Rhinoconjuctivitis is uncommon and more usually asscociated with constitutional asthma.

This paper was originally published as part of the Public Health module in the RCPE Online Continuing Medical Education Programme. Online CME, including the anwers to these questions, is available to Fellows and Members at: http://www.rcpe.ac.uk 